\title{
Documentalismo, reescritura y apropiación en la poesía chilena reciente ${ }^{1}$
}

\section{Documentalism, Rewriting and Appropiation in recent Chilean Poetry}

\author{
Biviana Hernández \\ Universidad de Playa Ancha \\ biviana.hernandez@upla.cl \\ Claudio Guerrero \\ Pontificia Universidad Católica de Valparaíso \\ claudio.guerrero@pucv.cl
}

\section{Resumen}

En este artículo convergen dos investigaciones en curso en torno a la poesía chilena de posdictadura. En él, se emplea la categoría crítica de documentalismo para referir el estudio de los procedimientos de reescritura y apropiación que utilizan los poetas Jaime Pinos, María José Ferrada, Óscar Barrientos y Carlos Soto Román, autores que llevan a cabo un peculiar trabajo de montaje e intervención de fuentes documentales, a fin de producir una reflexión histórico-cultural acerca de cómo los medios masivos de comunicación modelan la realidad y el discurso público.

Palabras clave: Poesía chilena, posdictadura, documentalismo, reescritura, apropiación.

\section{Abstract}

In this article, two ongoing researches about post-dictatorship Chilean poetry converge. Within it, the concept of documentalism is used to denote the study of the rewriting and appropriation procedures used by poets Jaime Pinos, María José Ferrada, Óscar Barrientos and Carlos Soto Román, authors who develop a special work of montage and intervention of documentary sources to generate a historic-cultural meditation about how mass media building reality and public discourses.

Keywords: Chilean Poetry, post-dictatorship, documentalism, rewriting, appropriation.

1 Este trabajo forma parte de los Proyectos Fondecyt 11170009 "Reescribir o el comienzo de la escritura: poéticas del campo cultural chileno-peruano (1943-2014)" y 1170245 "Poéticas postdictatoriales. Memoria y neoliberalismo en el Cono Sur: Chile y Argentina”, de los cuales Biviana Hernández y Claudio Guerrero son Investigadores Responsables. 


\section{Introducción}

Existe en la poesía chilena una vasta tradición en el trabajo poético con fuentes documentales de diverso tipo. Mayoritariamente el documentalismo ha sido utilizado como una práctica de apropiación y reescritura, conformando una trenza con varios nudos, algunas de cuyas expresiones más visibles nos interesa recalcar en este trabajo.

El documentalismo como categoría crítica es un concepto amplio y plurisignificativo, y que, en sí mismo, merecería un trabajo de largo aliento. No es el caso trazar esa genealogía crítica aquí. Consideramos como un punto de partida, sin embargo, las iluminadoras ideas de Walter Benjamin, a partir de quien el documento ha sido entendido como expresión de la violencia simbólica de la historia, cuyo afán destructivo todo lo borra. Así lo expresaba Benjamin en "Sobre el concepto de historia" al sostener que "No existe un documento de la cultura que no lo sea a la vez de la barbarie" (43). Recuperar el pasado, entre otras cosas, es para Benjamin tantear el peligro, jugar con los muertos, recuperar la infancia. El documento, por tanto, vendría a ser la evidencia, el archivo, el material o el texto a través del cual el sujeto no conoce verdaderamente el pasado tal como ha sido, sino que en tanto apoderamiento de un recuerdo "tal como éste relampaguea en el instante de un peligro" (41). El documentalismo implica entonces una apropiación inestable y relampagueante del documento, apenas una luz perdida, punto de partida para un ejercicio de escritura poética que deviene otra cosa, a partir de su reutilización dislocada, fragmentaria, en cuanto parte de un proceso de montaje que es condición de su resignificación.

Documento: punto de partida, potencia. Apropiación: juego creativo, tarea poética, construcción, proceso. Reescritura: diálogo, relación, intercambio, relectura, resignificación. Gustavo Guerrero, en sus Paisajes en movimiento (2018), afirma que la reescritura equivale a reapropiación, a volver a escuchar, a hacer oír las voces del pasado o a "hacerlas oír diferentemente, sin escatimar la distancia que ahora nos separa de ellas" (63, cursiva en el original). Desde el gesto de reapropiación, los usos de la reescritura en la poesía chilena contemporánea han resignificado las técnicas de proceso, construcción y juego del arte conceptual (Gache 2016) por medio de una estética procesual que presta atención a la autoconsciencia de la propia naturaleza y funcionalidad significativa de la obra (Marchán Fiz 1994), cuando ella encarna una ética "donde la construcción o concepción del texto es tan importante como lo que el texto dice o hace" (Goldsmith 22). En este marco, la ficción moderna del sujeto creador no solo ha dado paso a "una directa incautación, a la cita, a la extracción, acumulación y repetición de imágenes ya existentes" (Crimp 70), sino también al acto de escribir como "acto de mover el lenguaje de un lado a otro" en tanto se considera que "el contexto es el nuevo contenido" (Goldsmith 24, cursiva en el original), y que el escritor de hoy se asemeja a un programador "que conceptualiza, construye, ejecuta y mantiene de modo brillante una máquina de escritura" (Goldsmith 22), una máquina generadora de "ideas complejas sobre la identidad, los medios y la cultura" (Goldsmith 24-30). 
Esta forma de producción, por una parte, tiene múltiples antecedentes dentro del campo poético chileno del siglo xx: los poemas-collage del Quebrantahuesos, los Artefactos de Nicanor Parra, El Paseo Ahumada y La aparición de la virgen de Enrique Lihn, el Proyecto de obras completas y Declaración jurada de Rodrigo Lira, La Nueva Novela de Juan Luis Martínez, los Poemas encontrados y otros pre-textos de Jorge Torres y Naciste pintada de Carmen Berenguer, por mencionar solo algunas obras que apelan a una relación social dinámica con un lenguaje en uso constante - el de los medios masivos y las nuevas tecnologías de información-. Repertorio al que podrían sumarse otros textos y autores que han utilizado la reescritura desde la apropiación de formatos burocráticos o géneros discursivos primarios (Bajtín 1982); entre ellos, Carlos Cociña, con el texto de divulgación científica; Bruno Vidal, con el soporte de los bandos o partes militares; o la ya mencionada Carmen Berenguer, con el formato periodístico, especialmente la crónica y la entrevista, que también han empleado Rosabetty Muñoz, Jaime Huenún, Leonardo Sanhueza, Christian Formoso, César Cabello y Verónica Jiménez, entre varios otros. ${ }^{2}$

La tendencia a una poesía documental, por otra parte, en especial la de más reciente data, la entendemos en clave epocal en cuanto a la necesidad de urdir sentidos expresivos que tensionen estéticamente fenómenos sociales y políticos actuales. Fenómenos que guardan relación tanto con las fisuras de la transición a la democracia y los devenires de la posdictadura, como con el tratamiento espectacularizado de los mensajes que emiten los medios de comunicación. La subjetivación crítica del inasible e imposible objeto llamado Chile neoliberal es un procedimiento susceptible de tensar desde la poesía que se viene editando y publicando en nuestro país durante los ya veinte años del siglo xxI, especialmente aquella que apela a la contingencia y a un pasado reciente, en donde lo dictatorial perdura en varios sentidos acompañado del prefijo pos, entendido este último, en consonancia con Nelly Richard, como resto, residuo, permanencia silente y fantasmal. Esta poesía documental, cronística, enfocada en comprender y desanclar el glosario que nos rige de manera hegemónica, es posible de hallar en algunos textos poéticos de autores de diferentes promociones, como Elvira Hernández, Juan Carreño, Alejandra González, Raúl Hernández, José Ángel Cuevas, Mauricio Redolés o Daniel Tapia, además de los poetas antes mencionados, que servirían como precursores de esta modalidad estética basada en el trabajo creativo con diversos documentos.

Para efectos de este trabajo, nos centraremos en la producción poética con fuentes documentales de cuatro poetas chilenos nacidos en la década del setenta, y cuyas primeras publicaciones vienen de los años noventa y dos mil hasta ahora. Nos referimos a Jaime Pinos (1970), María José Ferrada (1977), Óscar Barrientos

2 Reconocemos, asimismo, un creciente interés colectivo por la reescritura que han continuado los desarrollos de los proyectos anteriores, en obras como Desencanto personal: reescritura de Canto General de Pablo Neruda (2006), Memoria poética. Reescrituras de La Araucana (2010) o Neoconceptualismo. El secuestro del origen (2001). 
(1974) y Carlos Soto Román (1976). En ellos, el documentalismo en tanto estética procesual, como método de elaboración o realización de un lenguaje artístico, activa variadas formas de apropiación y reescritura con materiales de diversa procedencia, funcionando como una puesta en escena que permite renovar, problematizándolos, los códigos tradicionales del lenguaje poético asociados a las categorías modernas de autoría, subjetividad y originalidad.

Almanaque (2010) y Documental (2018) de Jaime Pinos, Notas al margen (2013) de María José Ferrada, Rémoras en tinta (2014) de Óscar Barrientos, y 11 (2017) de Carlos Soto Román, son obras literarias que, junto con tensionar su estatuto genéricodiscursivo desde la autorreflexión crítica en torno a sus propias condiciones de producción/enunciación, recuperan territorios asediados por la tradición de la vanguardia y la escritura conceptual ${ }^{3}$ al emplear técnicas de proceso, construcción y juego que enfatizan su condición material y procesual de objeto, idea, proyecto, investigación o realización formal. Estas obras se apropian de objetos y materiales ya existentes en los discursos y medios de información masiva, tratándose de expresiones que pueden ser leídas desde la categoría de poema encontrado, ${ }^{4}$ como objeto intervenido o estetizado por la palabra, previa selección de un conjunto amplio y variado de noticias de prensa, sobre las cuales los poetas-reescritores aplican técnicas de corte, recorte, variación, montaje e intervención.

A partir de la intervención de textos anteriores de naturaleza no literaria, en una relación social dinámica con un lenguaje en uso constante, especialmente el que deriva de los medios de comunicación, estos poetas exhiben no solo sus materiales de trabajo, sino también sus formas de construcción/producción discursiva. De manera tal que la apropiación del lenguaje que deriva de ello no solo indaga en las condiciones de producción actual de la poesía, en los usos "expandidos" de sus lenguajes y códigos, a partir de los vínculos con la imagen y la cultura digital a la que pertenecen y con la que se identifican muchos de estos escritores, sino que también formula - aun en la renuncia a la idea de originalidad y de voz personal - una dimensión ética que releva los vínculos entre poesía y política, cuando el escenario que los modula - el de la posdictadura - hace depender la producción de subjetividad del tejido social que la enmarca y configura desde el exterior.

3 Desde los planteamientos de K. Goldsmith, entendemos la poesía conceptual como un proceso no creativo en el que conviven el gesto rupturista y experimental de la vanguardia con las nuevas tecnologías digitales y de la información; un proceso cuyas estrategias principales son: "no originalidad, ilegibilidad, apropiación, plagio, fraude, robo" (Padilla 398), y sus métodos: "administración de información, procesamiento de textos, bases de datos, archivo y catalogación" (398). Para Padilla, el poeta conceptual trabaja con el archivo (con el documento, diremos nosotros) para resingularizar lo homogéneo (399).

4 Recordemos que para Bürger (1974), la posvanguardia literaria y artística estuvo ligada al surgimiento histórico del ready-made u objet trouvé, es decir, a la técnica donde comenzó a primar la superposición de materiales externos a la obra dentro de la obra, y su disposición en el espacio compositivo del marco o de la página, antes que en la subjetividad creadora como demanda de los principios románticos, místicos e idealistas de la representación cultural moderna. 


\section{Documentar la barbarie: Jaime Pinos}

En Criminal (2003), Jaime Pinos ${ }^{5}$ ya había inaugurado una propia línea estética centrada en la realidad histórico-material. Este libro aborda desde diversas voces, recurriendo a un collage de textos no literarios, como encuestas, informes psiquiátricos y notas de prensa, la historia de Roberto Martínez, El Tila, un joven criminal santiaguino que durante el año 2002 captó la atención de los medios de comunicación por un par de violentos asaltos con violación y descuartizamientos que perpetró en algunos sectores de la capital chilena, principalmente en uno de los más acomodados, como La Dehesa. El Tila había obtenido premios literarios mientras vivía en hogares del SENAme (Servicio Nacional de Menores) y sus poemas habían salido publicados en la revista Ya del diario El Mercurio, que el periódico emitía una vez a la semana, y dirigido principalmente a un determinado estereotipo de mujer. Estando preso, solicitó una máquina de escribir, y con la cinta, pocos días antes de ser sentenciado a cadena perpetua, se ahorcó.

Su caso resultó emblemático para confirmar el proceso de generación de un clima de inseguridad que durante los gobiernos de la Concertación por la Democracia de los años noventa contribuyó a armar el grupo económico en torno a Agustín Edwards, el dueño de El Mercurio, el principal diario nacional que instigó el golpe de 1973 y que fue cómplice durante la dictadura cívico-militar de montajes de noticias, omisión, manipulación y ocultamiento de información. Edwards y colaboradores de distintos sectores políticos, incluso un exministro de Allende como Sergio Bitar, preso político en la patagónica Isla Dawson, crearon el 2 de abril de 1992 la Fundación Paz Ciudadana, la cual se encargaría de entregar periódicamente datos sobre victimización de personas, con gran resonancia mediática. En este contexto, en donde la delincuencia pasó a ocupar la principal agenda de los medios, el Tila es recogido retóricamente como "una hipérbole de la segregación de la ciudad" (Sepúlveda 151), al convertirse mediáticamente en uno de los más emblemáticos casos de la historia de la crónica roja en los inicios del nuevo milenio en Chile. Su figura confirmaría la creciente sensación de inseguridad de la población que modificó de manera paulatina y para siempre la convivencia cotidiana, recluyendo a las personas hacia adentro, para estar a resguardo: poco a poco fueron creciendo las rejas, se fueron cerrando pasajes, despoblando las plazas y la gente caminaba por la ciudad con miedo, en un proceso de desterritorialización que se alineó con las paulatinas dinámicas de individualismo y competitividad que fomenta el neoliberalismo a la chilena.

En Almanaque (2010), su segundo texto poético, Pinos desmonta algunos de estos discursos imperantes trabajando con la historia reciente como material concreto de

5 Ha publicado la novela Los bigotes de Mustafá (1997) y, aparte de los textos que se comentan acá, el proyecto multimedia 80 días (2014), la recopilación de textos críticos y ensayísticos Visión periférica (2015) y la antología poética Trabajo de campo (2017). 
trabajo. Se trata de una visión que, en palabras del propio Pinos, busca "metaforizar la historia”, ocupando el poeta el rol de investigador y usando la poesía como soporte documental. En un texto leído en Viña del Mar en octubre de 2015, en el contexto del III Seminario de Estudiantes de Castellano: Degradación y resistencia; espacios de la poesía en el siglo xxi, y que tituló "La poesía. La historia. El relámpago", Pinos reconoce en los poetas norteamericanos Ed Sanders, Charles Olson, Charles Reznikoff y Muriel Rukeyser una filiación genealógico-estética que considera al poeta como un investigador y un documentalista. El origen de la poesía documental se remonta, al menos en la tradición anglosajona, hacia los años treinta con los postulados objetivistas de Ezra Pound y Charles Olson. Su pervivencia se expresa a lo largo del siglo $\mathrm{xx}$ bajo distintas modulaciones y reconsideraciones. De estas expresiones, uno de los textos que resulta significativo para este trabajo, es "Poesía investigativa” (1976), de Ed Sanders, el cual podría funcionar como uno de los textos-base para la consideración de lo que podríamos denominar el método documental.

Es sintomático, por otra parte, que precisamente hacia fines de los años setenta y comienzos de los años ochenta poetas chilenos como Parra, Lihn o Juan Luis Martínez promoviesen un trabajo estético sobre la base de documentos. Señero resulta, para este efecto, la caja-instalación diseñada por Martínez que denominó $L a$ poesía chilena (1978), en donde se puede encontrar, entre otras cosas, una muestra de tierra del Valle Central de Chile, banderas chilenas en papel volantín y copia de los certificados de defunción de Mistral, Neruda, De Rokha y Huidobro. La poesía documental, en consecuencia, tendría un momento de eclosión al menos desde los años setenta cobrando un sentido expresivo, en el caso de la poesía chilena, en el contexto dictatorial a partir del cual expresa un mayor desarrollo, persistiendo hasta hoy en la posdictadura, bajo nuevas consideraciones.

Esta reelaboración de una poesía documental adquiere en Pinos un nuevo sentido: “Trabajar con documentos. Trabajar con evidencias. Reconstruir la historia a partir de unos vestigios rescatados al olvido. Conservados como señales para reconstruir el pasado, para recomponer su imagen y su relato" (Pinos, "La poesía"). Tanto Criminal como Almanaque han sido concebidos y funcionan, por tanto, como poesía documental, como poesía que pretende dar cuenta de la historia: una memoria viva del proceso chileno de neoliberalización en algunas de sus aristas más susceptibles de ser desmontadas. Al respecto, señala el sujeto de Almanaque en el poema "Erradicación":

A la Gente Pobre se le comunica

que ha terminado la Ocupación Ilegal.

Que desclave sus mediaguas.

Que embale sus enseres.

$[\ldots]$

No en mi patio trasero, han dicho los vecinos de los Condominios,

asustados por el alza de la delincuencia,

asustados por la baja de la plusvalía (25). 
La violencia, la desvinculación afectiva entre las personas, la desconfianza y el egoísmo, el individualismo, el miedo a un otro indeterminado con características delictuales, y la pobreza como sospecha o estigma son algunos de los elementos que aquí se resaltan, emulando el lenguaje autoritario de un edicto, en términos de ultimátum. En el poema "Música ambiental", en tanto, un trágico hecho noticioso, el suicidio de una joven el 4 de mayo de 2006 en el lujoso mall Alto Las Condes de la capital, da paso a la asunción de una voz irónica que critica el contradictorio hiperestímulo sinestésico de los centros comerciales, que desencadena un sueño hipnótico, deshumanizado:

$$
\begin{aligned}
& \text { los consumidores } \\
& \text { pasean en familia } \\
& \text { por pasillos saturados } \\
& \text { luces, colores, íconos, textos, } \\
& \text { mercancías, torres de cosas, } \\
& \text { les flanquean los pasos, } \\
& \text { el vidrio de las vitrinas } \\
& \text { refleja sus rostros, } \\
& \text { les gana los ojos } \\
& \text { su resplandor hipnótico (31). }
\end{aligned}
$$

El plácido paseo familiar en la "catedral del consumo" (Moulian 55), acompañado de una sugerente música ambiental es contrastado en este poema con el grito ahogado de una joven de 24 años dando término a su propia vida. Ambos textos poéticos muestran algunas de las heridas o fisuras del sistema neoliberal: la pérdida del entramado social y de sentido en el deseo de consumir, desafección, soledad. La exhibición de estas "fallas" del modelo junto a otras como la precariedad laboral, el endeudamiento, y la falta de memoria y justicia respecto a las víctimas de la dictadura son algunos de los documentos con los cuales Pinos configura un trabajo escritural que resignifica el Chile reciente. Señala la voz poética en otro texto titulado "Nota al margen":

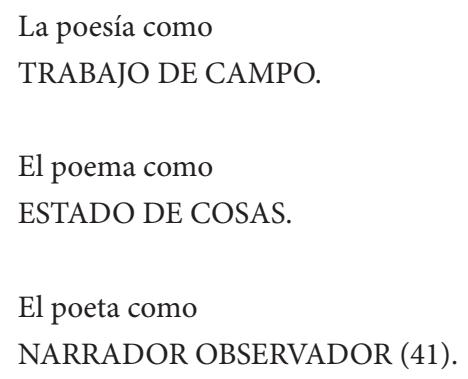

Como en la poesía de Enrique Lihn y en la de los nombrados poetas estadounidenses, el arte poética que concibe Pinos guarda relación con un ejercicio de escritura que debe ocupar un lugar en el entramado social: una tarea que posibilita documentar la realidad y establecer su crónica. En este proceso, el sujeto se retrotrae, se retira, para que, 
en su posición de observador del estado de cosas, en el lugar del etnógrafo que ocupa un margen, como fuera de escena, elabore un nuevo documento a partir de sus notas.

El último trabajo de Pinos, en este sentido, vendría a coronar esta propuesta de una poesía sociológica en una suerte de summa poética. No deja de ser sintomático que se llame, justamente, Documental (2018). En este poemario, Pinos vuelve a trabajar con periódicos, archivos con nombres de exagentes de inteligencia del Ejército, imágenes fotográficas tanto personales como de registros del bombardeo a La Moneda, incluso con fragmentos de novelas de Mariana Callejas, exagente de la DINA, entre otros tipos de documentos. De manera alternada, al igual que en Almanaque, el lector se encuentra con poemas metaliterarios cuya reflexividad revela la racionalidad preponderante tras el manejo de los materiales. En una de las páginas de Documental se lee: "el material del montaje no es en absoluto arbitrario / el montaje auténtico descansa sobre el documento" (s. n.). Como portador de su propia teoría, la poesía de Pinos construye un archivo que cumple a la vez una doble función: por una parte, se muestra a sí misma en la tarea de no olvidar, en la construcción de una voz cuyo mandato es el de constituirse en la memoria histórico-poética del Chile reciente; por otra parte, esa misma materia inicial, el documento que da pie al trabajo escritural, es la base que permite hacer dialogar la experiencia biográfico-histórica, en clave generacional, con una experiencia estética que concibe el arte, y la poesía en específico, como un interviniente concreto en la configuración del mundo social.

\section{El poema como nota al margen: María José Ferrada}

Desde su título, Notas al margen $(2013)^{6}$ de María José Ferrada ${ }^{7}$ resulta un poemario tan extraño como sugerente. Al abrirlo, nos encontramos con un volumen ilustrado ${ }^{8}$ que la crítica ha considerado para un público infantil, quizás por la trayectoria literaria de la autora y, particularmente, por la publicación de su poemario Niños (2013), donde rinde homenaje a los niños desaparecidos en dictadura; pero en Notas al margen, salvo por las ilustraciones, no es tan claro que este sea un libro infantil o dirigido a este tipo de público. En él, la figura del infante es transversal, como lo demuestra el mapamundi que sigue al índice del poemario, donde los continentes, países y ciudades capitales del mundo son representados con ilustraciones de animales, seres fabulosos y niños.

6 Nótese, entre otras cosas, el vínculo semántico con el comentado poema de Pinos.

7 Ha publicado, además, la novela Kramp (2017), ganadora del Premio Municipal del Consejo Nacional del Libro y la Lectura en la categoría Mejor Obra Publicada (2018). Entre sus obras de literatura infantil y juvenil destacan: Historias minúsculas de la tierra, el cielo y el mar (2005), Mundo raro (2010), El lenguaje de las cosas (2016), El baile diminuto (2012), Animalario (2012), Geografía de Máquinas (2013), Pájaros (2016), El interior de los colores (2017), La infancia de Max Bill (2016), La tristeza de las cosas (2017), Sábados (2018) y Guardianes (2018).

8 Las ilustraciones son de Francisca Yáñez (1971), ilustradora, diseñadora gráfica y artista visual para diferentes editoriales e instituciones relacionadas con cultura, infancia y derechos humanos. 
En Notas al margen, el sujeto infantil es imaginado y nombrado por una subjetividad adulta mediante una operación de montaje que superpone en el espacio de la página tres tipos de textos: una noticia de prensa, un poema y un dibujo. Siguiendo este esquema compositivo, el poemario se divide en cinco secciones: "Lejanías", "Silencios", "Paisajes", "Infancias" y "Pequeñas revoluciones", las cuales, al final del texto, aparecen acompañadas de un extenso catálogo de referencias en línea que llevan a los sitios web de donde se han extraído cada una de las noticias que ha servido de fuente o modelo para la reescritura de los poemas. Una pregunta inicial que resulta tras esta observación es si los poemas de Ferrada dependen de la noticia y, por lo tanto, si estas son o constituyen el material central de Notas al margen o, bien, si las notas al margen del poemario corresponden a los poemas del libro, como si estos fueran poemas-notas, poemas-glosas o poemas-sumillas que interpretan, decodifican o traducen las noticias encontradas (leídas y/o escuchadas) en distintos medios de comunicación. La respuesta, por cierto, no es una ni única. Se podría decir, a primera vista, que el montaje opera conforme a una relación de coordinación o complemento y que, en tal sentido, los tres elementos de su composición, la noticia, el poema y la ilustración, son interdependientes unos de otros; pero, al releer, surge la duda, puesto que los poemas, si bien mantienen cierto vínculo temático o referencial con las noticias, no guardan con ellas una relación de fidelidad que permita considerarlos como dependientes de aquellas.

Hay varios poemas al interior del texto - los más breves, sobre todo- que nada dicen, de forma explícita, sobre el contenido de la noticia que los acompaña. Es el caso, por ejemplo, de los poemas III y v de la sección "Silencios". "SILENCIO en la tierra" (30) es el primero, y "SILENCIO en el mar" (34), el segundo. Frente a la brevedad y contención expresiva de estos versos, las noticias que ellos llevan aparejados son, por el contrario, extensas y profusas en volumen y contenido de la información. ${ }^{9} \mathrm{De}$ modo que la operación de recorte/variación es, en estos casos, extrema. Se reduce a su mínima expresión lo referenciado en el cuerpo de las noticias al punto que resulta imposible reconocer las fuentes o establecer algún tipo de relación directa con ellas, aun cuando se las haya leído o escuchado previamente y se coteje su existencia como documento o archivo en distintos medios de información impresa y digital.

Con estos ejemplos, podríamos decir que el ejercicio productivo, dialógico y relacional de recurrir a un texto previo, anterior, de carácter no literario, para producir otros nuevos, remite a una práctica de comunidad donde el o la poeta-reescritor(a) actúa al modo de un reciclador que lee cuidadosamente su realidad y, con cuidado, "copia, recicla y se apropia del discurso público para participar en diálogos textuales, inter

9 La primera noticia (poema III) se refiere a las denuncias de UNICEF (Fondo de las Naciones Unidad para la Infancia, 1950), indicando la cantidad de niños que mueren al día en Chile por causas evitables. La segunda (poema v), se refiere a la "ola asesina" que en las costas de Galicia provocó el hundimiento y posterior derrame de petróleo del buque petrolero Prestige en 2002. Ambas noticias documentadas entre 2012 y 2013, por Radio Cooperativa y el diario El País, respectivamente. 
y extratextuales más amplios” (Rivera Garza 93), diálogos que llevan a preguntarnos por lo que el poema y el poeta selecciona y descarta, en circunstancias en que, desde su título, nos enfrentamos a él desde una operación de reescritura/intervención por apropiación del formato periodístico que lo transforma discursiva y simbólicamente.

Con respecto al formato, es sabido que la nota al margen corresponde a una técnica de estudio utilizada para hacer anotaciones en los márgenes de las hojas de un libro. En las notas se coteja, brevemente, la idea fundamental de cada párrafo leído. En esta dirección, Notas al margen parece llevar a la práctica las varias posibilidades de esta técnica: como nota marginal (o sumillado), los poemas del libro se realizan en el propio texto de la noticia o junto a él, en forma paralela, desarrollando la capacidad de análisis y/o de síntesis con respecto a la idea central de las noticias que se emplean como material de base (o documento) para la reescritura poética. La nota al margen, por tanto, es una síntesis, una hipótesis o supuesto de lectura, una pregunta abierta, una idea sugerida por las claves léxico-semánticas del texto, una interpretación o valoración de estas. No obstante, en todos los poemas de Notas al margen la noticia no solo resulta intervenida — con un sentido de actualización, revisión o comentariopor el lenguaje de la poesía, sino también desbordada de su ámbito referencial como texto de uso informativo. Podríamos decir que la poesía o los poemas como notas al margen materializan eso que Jaime Pinos, en su poema "Nota al margen”, atribuía al rol ético-poético del escritor: el (deber) ser un trabajo de campo, un estado de cosas.

Veamos, por ejemplo, el primer poema del volumen que versa sobre una noticia publicada en el diario El País, el 4 de diciembre de 2011. En el titular "Hikikomori, perdidos en su habitación" se detalla en el cuerpo de la misma como sigue: "la competitividad y presión social están creando una nueva especie humana en Japón: inadaptados que sufren tal fobia por la comunicación, que se encierran durante años en su cuarto. Solos. No hablan. No salen ni para comer. No les gusta el mundo y se refugian en videojuegos, cómics y libros" (Ferrada 13). La voz poética, por su parte, imagina, respecto de la noticia, a una niña encerrada en su habitación, Hikikomori, mirando el mundo a través de su ventana e imaginando que ese mundo es una ficción, un sueño, un invento de su fantasía. Como en una puesta en abismo, el poema intenta acortar la distancia que separa al observador de lo observado, esto es, a la niña del poema, la que mira por su ventana, de los ojos de la hablante que ven o repasan las líneas del texto de la noticia y de sus propios versos, apropiándose así de la impersonalidad del registro noticioso para construir una tercera persona gramatical sobre la cual recaerán los efectos de esa "anomalía social" que descansa en los "inadaptados que sufren fobia por la comunicación”:

I

Mira por la ventana de su habitación.

Cuando era pequeña observaba desde ese mismo rectángulo.

Pensaba que los neones se parecían en algo a las luciérnagas.

Los insectos. 
Su madre, un moscardón. Su padre, grillo mudo.

[...]

Cricricri, tzzzzzz, tzzzzzz. Cricri. Tzzzzzzzzzz.

La última vez que salió de su habitación fue dos años atrás.

Era primavera. Tiempo de libélulas (12).

Si se atiende al tono lírico del poema, reforzado por el uso de la onomatopeya que reproduce los sonidos de los insectos que representan a los padres (un moscardón y un grillo mudo), percibimos que los versos, en tanto notas al margen, no son de tipo analítico o sintético. La voz poética no busca analizar o resumir el contenido del texto periodístico, sino que en el acto de leer está transformando ese texto en otro registro comunicativo y verbal. Dicho de otro modo, Ferrada lee, interpreta, escribe e interviene sobre lo leído o escuchado, elaborando una versión propia del conflicto socioafectivo que presentan las noticias acumuladas en su elenco o catálogo de lecturas periodísticas, previamente seleccionadas. La intervención modifica el discurso del texto original, desestabilizando su sistema de valores (Buksdorf 97), en la medida en que los poemas resultantes producen un excedente de sentido respecto de la información que aporta el medio de origen (el periódico, la radio, la televisión, Internet), haciéndolos funcionar de manera autónoma.

Por otra parte, respecto de la dimensión simbólico-ideológica de los poemas, cabe aclarar que Notas al margen se posiciona críticamente frente a la coyuntura política del neoliberalismo y la globalización. En él, los tópicos de la infancia y la ciudadanía giran en torno a la contingencia histórica de los años que enmarcan la producción del texto: derechos humanos, inmigración, deportaciones, violencia de género, guerras civiles, lenguas y pueblos indígenas masacrados, desprotección de la infancia, desigualdad social, precariedad e indigencia. Problemáticas que en el poema número II de "Lejanías" son abordadas desde la situación de los inmigrantes peruanos en Chile. Remitiéndose al diario La Hora del 21 de junio de 2010, la noticia, breve, solo consigna una cifra: "El subsecretario de Investigaciones, Mario Desbordes, estimó en 90.000 los inmigrantes peruanos en Chile [...] De esta cifra, 67.000 estarían de forma legal, mientras que 23.000 residen ilegalmente" (15). Mientras que el poema elabora una nostálgica descripción del largo viaje que emprenden los sujetos migrantes en busca de mejores condiciones de vida: "II Tiran migas de pan por la ventana del bus en el que / atraviesan el desierto para dibujar un cielo estrellado, / un camino en medio de la arena" (14). El impacto de la estadística contrasta en este caso con el sentido de promesa que transmite la palabra mediante la plegaria compartida por las mujeres en la difícil travesía de cruzar el desierto, con la esperanza de un nuevo y mejor futuro:

Una a otra -el viaje es largo-, las mujeres se enseñan

la plegaria:

"Dios de los pequeños, que juegas en un río de la noche, 


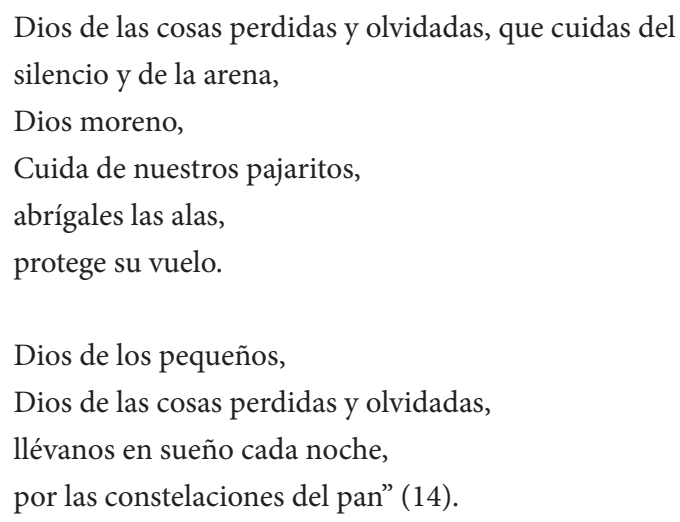

Del mismo modo en el que este poema describe, desde la metáfora del hambre, la falta de alimento y sustento para el sujeto migrante, el poema número vi de la misma sección gira en torno a una noticia de la BBC Mundo, del 11 de enero de 2005: "Mendigos en tierra de abundancia", en la que se hace referencia a la situación de indigencia que padece un alto porcentaje de la población civil en Estados Unidos: "Se estima que alrededor del uno por ciento de la población se queda sin hogar en algún momento a lo largo de un año cualquiera" (23). El yo poético, distante de la información suscrita en el texto, imagina a un individuo cualquiera en su primer día como indigente:

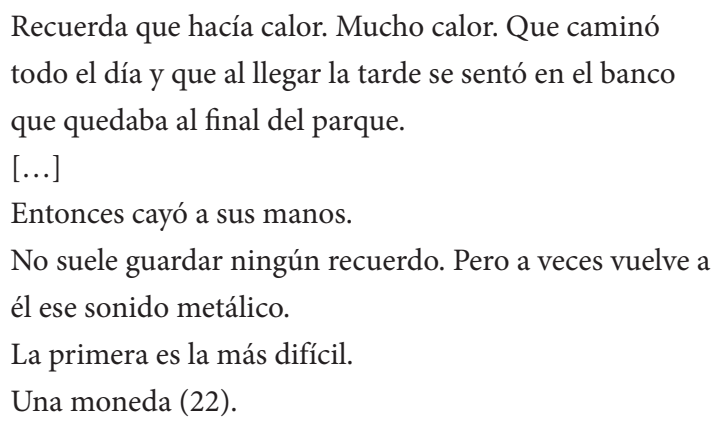

Ferrada utiliza la noticia como una excusa para reflexionar sobre el mundo de lo común que emplaza las relaciones de sobrevivencia en un sistema de poder que vulnera los derechos humanos de quienes son considerados vida nuda, desechable. La escritora expresa su interés por reflexionar críticamente sobre esta situación, ampliando no solo las posibilidades de lectura, comprensión y sensibilización de las noticias intervenidas, sino también su valor de uso social para la poesía, en la medida en que el acto de intervención sobre un registro comunicativo de carácter popular y masivo es aquí un llamado de atención al ciudadano promedio, que consume pasivamente la información que circula por los medios, para que tome conciencia activa de la situación social descrita y, como en el poema, decida intervenir sobre ella. 
La autora, antes que apropiarse de o intervenir sobre sus materiales de trabajo, refuncionaliza el lenguaje que actúa como marco o contexto de producción para la elaboración de sus notas al margen, por lo que la supuesta relación de complementariedad o coordinación entre la noticia, el poema y la ilustración, resulta cuestionada o extralimitada. Los poemas de Ferrada parecen tener vida propia y no requerir de la lectura previa, paralela o simultánea de las noticias que actúan en calidad de documentos para la reescritura y, en tal sentido, como pie forzado de la enunciación. Lo mismo podríamos decir de los dibujos que los acompañan. Probablemente, a nivel de poética o proyecto de escritura, la construcción textual del poemario se comprenda mejor desde el uso y desborde de la técnica del montaje, pues, así como Jorge Torres en los 90 cortaba y pegaba los recortes de prensa donde circulaba el trauma de la historia política de un Chile en dictadura, María José Ferrada, en los 2000, intenta enmarcar la crisis de la posdictadura en una poética de "comunidades discursivas", donde los lenguajes del arte y la literatura conviven con los de los medios y las nuevas tecnologías de la información.

\section{Un memorial de recuerdos olvidables: Óscar Barrientos}

Más allá de un explícito homenaje-reescritura de Poemas encontrados y otros pretextos (1991) de Jorge Torres, Rémoras en tinta (2014) de Óscar Barrientos ${ }^{10}$ se articula como un collage textual sobre la base de un conjunto organizado de recortes de prensa que vinculan arte y política a través del gesto lúdico-crítico del montaje. Su estética del fragmento y el recorte implica que la selección del material (las noticias recortadas) pierde su función informativo-comunicativa inicial al ser des y recontextualizada en un nuevo escenario histórico y discursivo, donde juega el rol de un elemento de significación móvil, según su posición dentro del texto y su relación con todos los demás (Bourriaud 16), puesto que la acción de recortar implica suprimir el significado primario del recorte y su relación "original" con las partes que le siguen; valga decir que lo recortado pierde su relación de continuidad al quedar separado de la totalidad textual originaria, de modo tal que cada imagen, en su calidad de objeto encontrado $\mathrm{o}$, tal vez, buscado, pierde las relaciones contextuales, pudiendo entrar en asociaciones insólitas que logren sorprender al lector (Valdés 51).

El deseo latente de entretención más que de información contrasta con los discursos literarios que emplea el autor en dos citas-epígrafes que definen críticamente su noción del periodismo. La de Baudelaire: "no puedo entender que una mano pura

10 En poesía, Barrientos ha publicado Espada y Taberna (1988), Mi ropero es un mar sombrío (1990) y Égloga de los cantares sucios (2004), un libro con imágenes. En narrativa, entre otros, El diccionario de las veletas y otros relatos portuarios (2002), Cuentos para murciélagos tristes (2004), El viento es un país que se fue (2009), Quimera de nariz larga (2011), El barco de los esqueletos (2014), Trilogía de Puerto Peregrino (2015) y Saratoga (2018), tetralogía definitiva sobre Puerto Peregrino. 
pueda tocar un periódico sin estremecerse de disgusto" (Barrientos 25) pone de manifiesto su rechazo a priori del género o tipo de texto que genera la prensa. Mientras que la de Wilde: "la diferencia entre literatura y periodismo, es que el periodismo es ilegible y la literatura no se lee" (51) señala la condición de ilegibilidad y, por tanto, de no comprensión del lenguaje periodístico. No obstante, esta compilación de noticias insólitas, paradojales y absurdas, como las califica el mismo Barrientos, justifica su oficio de recolector de textos encontrados en los periódicos ${ }^{11}$ con los cuales confecciona el poema "Posmodernidad" que parece englobar el sentido cultural del texto:

Esa necesidad majadera

de morder todas las frutas

como buscando el gen de la historia universal

en la cabeza del alfiler.

[...]

"donde lo mismo un burro que un gran profesor"

[...]

Llenar de letras el crucigrama,

donde conviven el clavecín y la chuleta

es, después de todo,

un homenaje a la nada,

un memorial de recuerdos olvidables

o mirándolo bien,

un cementerio de latas de cerveza (10).

La incorporación de un extracto del tango Cambalache ${ }^{12}$ produce en el poema una versión irónica de la posmodernidad donde "Todo es igual / nada es mejor / lo mismo un burro que un gran profesor"; "Siglo veinte cambalache / problemático y febril el que no llora no mama / y el que no roba es un gil”. Pero el poema de Barrientos no solo habla de una posmodernidad problemática y febril, donde la usura y el robo son prácticas que legitima el "estado de cosas" que impone el neoliberalismo, sino que intenta él mismo emular su estética fragmentaria y residual para definir la condición epocal que enmarca la escritura poética en un tiempo determinado, el del cambalache, donde ese "todo" bien puede definir el deseo de los lectores que, en palabras del actor estadounidense Humphrey Bogart, "no quieren solo noticias, quieren historietas, crucigramas, concursos. Desean saber cómo hacer un pastel o tener amigos, prever el futuro, leer horóscopos, apuestas en las carreras, la interpretación de los sueños, cómo ganar la lotería y, si alguna de aquellas casualidades tropieza con la primera página, noticias" (Barrientos 7).

\footnotetext{
11 Las noticias provienen de diarios como La Segunda, La Nación, El Magallanes y varias páginas de Internet. Hay otras en que no se indica fuente ni fecha. La mayoría data de 2013, con un intervalo que parte en 2005.

12 Tango argentino compuesto en 1934 por Enrique Santos Discépolo para la película El alma de bandoneón.
} 
De esa posmodernidad del espectáculo y el divertimento habla a continuación el "memorial de recuerdos olvidables" que aporta la selección de noticias y su consecuente trabajo de montaje y edición. De forma individual, los poemas-collage del conjunto proceden por recorte y variación: cada noticia reproducida en el texto va acompañada de un poema creado por el autor que modifica el título y cuerpo de la misma. Así, por ejemplo, el titular "Hombre gana demanda contra su esposa por darle hijos feos" se transforma en la noticia poetizada "Queja de Jian Feng"; "Reniega de su hijo al enterarse de que es un mamífero" en "Niño nutria"; "Hombre se disfraza de alfombra para robar al interior de tiendas" en "El hombre-alfombra"; "Los diamantes podrían literalmente llover en Júpiter y Saturno" en "Emprendimiento"; "Un tailandés se casó con su novia muerta" en "Promesa de bodas"; "Roedor gigante es mascota de familia estadounidense" en "Monólogo de Gary"; "Brutal: mató a tortuga marina varada en Arica para hacerse lámpara" en "Lamento de Chinchorro"; "Poeta puso a la venta sus testículos" en "Epitafio leído al paso"; "Murió poeta” en "Buscando a Jorge Torres en el mapa"; "Manuel Contreras será juzgado en ausencia en Francia" en "La mansa gracia”; "Lechuza causó corte de luz" en "El insecto de Edison"; "Irán: gobierno asegura haber enviado mono al espacio" en "Balada del mono astronauta"; "Dos vegetarianos adoptan un brócoli" en "Al pie de la cuna", y así sucesivamente con las veintidós noticias que contiene el libro.

Detengámonos en la noticia-anuncio "Cama de bronce: venden el catre de la abuelita. Incluye somier y se va por \$100 mil” (Barrientos 11), cuya versión poética corresponde a "Elogio de cama con ciudad debajo", la cual muestra el procedimiento lúdico-paródico de la reescritura por apropiación del formato ${ }^{13}$ pues, mientras el texto informativo exhibe el carácter cómico de la noticia, el poema lo deforma, transformándolo en una reflexión sobre la temporalidad y la existencia finita del ser humano: "Debo afirmar que existe en el esqueleto de la cama, / un metal que alambica las redes de la memoria / [...] / un movimiento de palancas industriales, / un laberinto robado a la placenta del crepúsculo." (12). El hablante, autodefinido como "un pellejo maltratado", parece asumir que las condiciones de representación de la palabra dependen de los procesos de reproducción técnica ("palancas industriales”) que, a su vez, permiten activar "las redes de la memoria", sin las cuales esta no sería posible.

Sobre este proceso de mediación entre tecnología y subjetividad, Germán Carrasco sostiene que la mirada "atónita y fascinada del poeta-documentalista" de Barrientos aporta un dato que no está en la noticia, saliéndose de su marco. Un fuera de cuadro de la noticia (Carrasco 75) que resalta desde el absurdo de situaciones cotidianas y de la burocracia institucional, hasta la espectacularización de la violencia que circula diariamente en los medios de comunicación. Bajo estas claves se puede leer el poema sobre la crónica “стс tiene un edificio de reyes", referida a

13 Hemos abordado la reescritura de formatos no literarios en Hernández. 
la inauguración del edificio de la Compañía de Telecomunicaciones de Chile (CTC), actual Telefónica, en 1993. Distante del cuerpo de la noticia-crónica, el poema tiene varias partes y sigue la forma de un diálogo entre la estatua de Balmaceda y la sombra del edificio corporativo, opacando el rostro del mandatario. La "estatua de un recuerdo sublime" se contrapone a la voz de un edificio que representa el éxito de la empresa privada y el actual ethos neoliberal que desborda lo económico. Así, mientras la estatua de Balmaceda se pregunta, nostálgica, “¿cómo invocar al corazón de la República?” (67), “¿por qué un teléfono ensombrece el parque?” o “¡adónde fue a parar el alfabeto esencial?” (69), la sombra de la Telefónica exclama, elocuente:

Usted ha llamado a la incipiente república de Chile.

$[\ldots]$

si desea acceder al elevado porcentaje de cobre que se gasta en anda a saber qué, marque 2

si desea comprar vino chileno de exportación,

marque 3

si desea postular a un empleo

marque 4

[...]

si desea un curso on line de empresario emprendedor,

marque 6

si no desea nada tome una soga y cuélguese de nuestro piso

doscientos ochenta y cinco

[...]

Yo me sé tres palabras a la perfección

AQUÍ

SOMOS

FELICES

$[\ldots]$

Bienvenidos a Chile S. A.

El reino de la prosperidad y el éxito.

Nuestro objetivo es servirlo con eficiencia (67-69).

El texto informativo de la noticia es apenas una excusa para someter las contradicciones del sistema neoliberal a un proceso de transformación textual que las modifica no solo en su sintaxis, sino también en la reflexión propia que se elabora de ellas, pero que no se deduce de las mismas (al menos no desde la primera lectura). El montaje y el diálogo entre ambas figuras mapean la situación de un Chile exitoso y emprendedor, construido sobre la base de una ciudadanía que, imaginando o creyendo que se trata de un acto de libre elección, solo debe "marcar" en su inconsciente la opción que mejor se acomoda al deseo privado de ser parte de esa prosperidad económica que cambió para siempre el "venceremos" colectivo por el "venderemos" individual. El poema - y 
el poemario en su conjunto- puede leerse, entonces, como una operación reiterativa no solo de lugares comunes sobre lo que significa hoy en día ser ciudadano chileno, sino también de "interferencias" en lo ya visto u oído, en lo ya dicho en el habla o en lo ya escrito en los medios.

Rémoras en tinta interviene sobre una serie de sucesos que tiñen el nexo entre "engranaje social, percepción y producción de subjetividad" (Padilla 392) cuando en el texto, corte, recorte y variación/intervención de la noticia emplazan la textura de un discurso fronterizo entre los códigos-lenguajes del registro periodístico y literario. De allí surge la pregunta por lo que se elige y descarta, por lo que se selecciona y recorta, por el exceso o excedente de significación que estos recortes de prensa sugieren y posibilitan en su "traducción" a la forma/función poética. Tal vez, en este gesto de traspaso y mediación de un registro/formato a otro, la escritura sea un pie forzado para hacer decir a la noticia aquello que esta, en su condición de discurso natural o transparente, oculta o sublima o, incluso más, un ejercicio de presión (Porrúa 2011) sobre los materiales que actúan en función de documentos, y que busca refuncionalizar su sintaxis a fin de expandir sus posibilidades de relación y significación estético-cultural.

El archivo de poemas encontrados que articula Rémoras en tinta se expresa, entonces, como un fuera de cuadro, en la medida en que la realidad social entra al espacio del objeto artístico, actuando como un marco de visibilización para esos materiales anónimos, provenientes de un afuera donde yacían silenciosos o ignorados. No obstante, el producto resultante - las rémoras en tinta o las notas al margen, como textos que dejan ver el trabajo con y sobre documentos, su hechura material y procesual resultado de un trabajo de campo- no se vuelve un objeto literario solo por la incorporación al poema de las imágenes massmedia, así como tampoco la realidad se hace artística porque esta resulte estetizada por el acto de apropiación/intervención del poeta documentalista, sino porque a partir de la composición de la obra aquella materialidad extratextual ingresa al poema en procesos de significación que implican una realidad social, representacionalmente inédita (Rojas 218).

\section{No olvidar: Carlos Soto Román}

En el caso de la poesía de Carlos Soto Román, ${ }^{14}$ creemos que desde sus inicios se caracterizó por la búsqueda de un lenguaje que posibilitara nombrar, a partir de la confluencia entre simbolización y capitalismo (Padilla), las grietas de la precariedad del Chile posdictatorial. Haikú minero, editado por La Calabaza del Diablo en 2006, y uno de los primeros trabajos de Soto Román, anticipaba la mediática tragedia de

14 Ha publicado, entre otras cosas y aparte de lo reseñado aquí, La marcha de los quiltros (1999), Cambio y fuera (2009) y Philadelphia's Notebooks (2011). 
los 33 mineros rescatados en 2010, en un episodio transmitido en tiempo real por la televisión con millones de televidentes subsumidos por el espectáculo heroico del rescate, digno de una novela de Julio Verne. El poemario, publicado cuatro años antes de dicho evento mundial, versaba sobre el rescate de unos trabajadores de la mina de oro San Andrés, ubicada cerca de Andacollo, en la cuarta región del país, en marzo de 1999. El hecho noticioso fue seguido con atención por el poeta para reflexionar sobre las condiciones laborales de los trabajadores de la mina y a partir de ahí establecer un paralelo con el trabajo precario del poeta. Al respecto, señala el sujeto de estos poemas: "El encierro parte del encierro [...] / el encierro parte / del momento mismo del menoscabo" (15); "El vocabulario es escaso" (18); "La propia escritura es el encierro" (31). Y la sobrevivencia es "una causa perdida” (52) que lleva a una escritura desesperada. En este contexto límite, donde se concibe el ejercicio poético como un acto de vida o muerte, escribir los "últimos momentos" (53), "sangrar la tinta" (53), "esculpir la piedra" (53) se vuelve un mandato que posibilitará "dejar grabado con simples palabras / todo nuestro desencanto" (53). La noticia, por tanto, se conformaba como el material que habría de posibilitar una reflexión tanto social como metapoética propiamente tal y, en tal sentido, como el espacio retórico que permitía la articulación de distintas identidades sociales a partir de la confluencia entre producción material y comunicación lingüística (Padilla 382).

Ese sentido del desencanto frente a lo brutal de la realidad, junto a una constante experimentación con objetos, archivos y materiales, se constituye como uno de los valiosos aportes de la trayectoria poética de Soto Román, rastreable en la mayoría de sus dispersas obras, producidas en diferentes materialidades como libros, plaquettes, autoediciones, registros audiovisuales, fanzines, hojas sueltas, entre otros. Uno de sus últimos trabajos: 11, libro autoeditado en 2017, recibió el tradicional Premio Municipal 2018 de la Ilustre Municipalidad de Santiago. Los poemas incluidos en esta obra, señala Soto Román en el colofón de este libro, "fueron elaborados a partir de material de audio y texto, encontrados en documentales, entrevistas, artículos y otros documentos de diversa índole" (s. n.). Algunas de las fuentes son: la Constitución de 1980, los informes de las comisiones Rettig y Valech, otros archivos de derechos humanos, documentos desclasificados de la CIA, entre otros. La materialidad cruza la topografía del libro desde su tapa y contratapa a base de carbón. En su interior, el lector se encuentra con un importante número de páginas con grandes espacios en blanco, sin numerar, con archivos borroneados y con diversos registros escriturales, cuyas voces polifónicas terminan por conformar una coralidad en torno a la historia reciente. Resuenan por allí, por ejemplo, frases televisivas que forman parte de una memoria colectiva ochentera: “¿Dispara Ud. o disparo yo?” (s. n.), “Ríe cuando todos estén tristes..." (s. n.), frases que rememoran tanto la imagen de Don Francisco en Sábados gigantes como del grupo de comediantes que formaban parte del Jappening con Já, entremezclados a manera de montaje entremedio de otros textos, que dejan a la vista la condición del poeta como un operador semiótico, capaz de producir "equi- 
valencia, identidad, realidad y legibilidad, sobre una matriz de tiempo frío, extenso" (Padilla 382).

El efecto que esto produce es el de la resignificación de la enuncialidad original como eco de un pasado que vuelve de manera siniestra: titulares históricos de diario (“Exterminados como ratas”, del diario La Segunda o “¡Corrió solo y llegó segundo!”, del Fortín Mapocho), bandos del Ejército, archivos judiciales, certificados gubernamentales, la fórmula química con la cual Eduardo Berríos - agente de la CNI y profesor universitario al mismo tiempo- experimentó con el gas sarín, arma química que había sido creada en Alemania en 1938 y, en definitiva, toda una serie de textos que hace de cada página de 11 una discontinuidad histórica a partir de un trabajo de la memoria (Jelin 2002), un proceso creativo de descomposición y rearticulación de textos, que no pretende ser conclusivo ni acumulativo ni sistemático, sino todo lo contrario: como expresión y resultado de un trabajo de archivo. Un trabajo de excavación que, como diría Walter Benjamin, nos trae las capas de pasado que la sociedad, la clase dominante, los discursos hegemónicos se empeñan en mantener enterradas: "Sólo tiene el don de encender en el pasado la chispa de la esperanza aquel historiador que esté traspasado por la idea de que tampoco los muertos estarán a salvo del enemigo cuando este venza. Y este enemigo no ha cesado de vencer" (42). El número once, en este sentido, se erige como un signo englobante, un architexto plurisignificativo que no acaba, que no se termina, que permanece anclado para ser revisitado una $y$ otra vez, según las operaciones de la memoria, precisamente para no dar cabida a la algarabía de los triunfantes. Un signo que, dadas las operaciones del olvido, se hace necesario renovar siempre en la memoria. Tomamos como ejemplo, considerando que el libro entero es la muestra, los enunciados que recuerdan lo que más tarde los medios periodísticos llamarían "el gol de la vergüenza”: Chile vs. Unión Soviética en un Estadio Nacional que por entonces había servido de campo de concentración, para un partido que no fue, por la no presentación del equipo ruso, y que otorgaba la clasificación del seleccionado nacional para el Mundial de Fútbol de Alemania 1974:

MARCADOR ESTADIO NACIONAL

21 DE NOVIEMBRE DE 1973

LA JUVENTUD Y EL DEPORTE

UNEN HOY A CHILE

COPA DEL MUNDO FIFA

1974

SELEC. DE CHILE 1

SELEC. U. SOVIÉTICA 0 
El poema, escrito con mayúsculas, viene a reemplazar la imagen fotográfica del antiguo tablero marcador del estadio. El poema no recurre a la retórica de la écfrasis. El poema es la imagen fotográfica, pero sin imagen. La reemplaza, se muestra tal como la imagen, centrada en la página, sin fondo visual. Puro texto, muestra desnudo, condensado, la ironía burlona del hecho siniestro, toda su violencia discursiva y simbólica, la operación de barrido de la historia, tarea que esta poética, precisamente, propone recusar. El poeta como historiador, desprovisto casi de toda ornamentación, ya lejos del juego retórico.

\section{Conclusiones}

Las obras comentadas en este trabajo recurren a una memoria que cifra en la escritura y en la reflexión poética un quehacer que dota de sentido la experiencia del Chile posdictatorial. Tratándose de poéticas cuyos distintos procedimientos textuales cuestionan los discursos del poder hegemónico al documentar, por una parte, las fisuras de un modelo que se muestra a sí mismo como exitoso y al reescribir, por otra, los fragmentos de la historia reciente en clave poética, en especial a partir de la utilización de diversos soportes documentales, provenientes, en su mayoría, de archivos oficiales y periodísticos.

Jaime Pinos utiliza esos materiales para documentar la barbarie. Su escritura poética es el punto de partida de una memoria colectiva situada, que se urde sobre la concepción del texto como documento o archivo. Lo mismo ocurre en María José Ferrada, cuya escritura expande esa memoria colectiva situada del Chile de posdictadura hacia otras territorialidades, donde se expresa la violencia simbólica del neoliberalismo globalizado. Óscar Barrientos y Carlos Soto Román, por su parte, elaboran un archivo de imágenes culturales en las que el poeta documentalista expresa la subjetividad de una mirada impersonal (si acaso "objetivista"), pero profundamente reflexiva y crítica sobre el mundo social que habitamos, haciendo del contexto histórico (el afuera del poema, la realidad extratextual) su materia de intervención poética.

En su conjunto los poetas asumen la autoconciencia procesual, material y funcional del lenguaje, a través de formas poéticas complejas que no solo evidencian un replanteamiento constante de sus lenguajes y códigos, sino que también suponen un radical desafío de las concepciones acerca de lo que puede ser o no poesía, en circunstancias en que la conciencia reflexiva - que piensa el Chile actual con distancia crítica - viene aparejada de estos procedimientos de escritura que renuevan una tradición de larga data, sin por esto perder su potencial estético. Antes bien, esta conciencia reflexiva potencia la dimensión ética de una materialidad significante que dirime su praxis en el doble flanco de lo estético/político. Desde ahí, los poetas ejecutan un intenso campo de trabajo o de prueba (Porrúa 2011) con los materiales "encontrados" y/o "buscados" en el mundo de lo común, desarrollando un interesante 
campo de exploración donde la palabra poética se relaciona con el mundo y con la necesidad de recuperación de su capacidad movilizadora.

En síntesis, se trata de poéticas documentales que somatizan la historia y la memoria del Chile actual mediante técnicas de reescritura y apropiación que intervienen desde el régimen de lo sensible (Rancière), en una función política de la poesía que estaría superando, tal como lo plantea Alicia Genovese en Leer poesía, la supuesta inactualidad y devaluación del fenómeno poético.

\section{Referencias}

Bajtín, Mijaíl. "El problema de los géneros discursivos". Estética de la creación verbal, Trad. Tatiana Bubnova. Buenos Aires, Siglo xxi, 1982, pp. 248-293.

Barrientos, Óscar. Rémoras en tinta. Santiago, Alquimia, 2014.

Benjamin, Walter. "Sobre el concepto de historia". La dialéctica en suspenso. Fragmentos sobre la historia. Traducción, introducción, notas e índices Pablo Oyarzún. Santiago, LOM, 2009, pp. 37-83.

Bourriaud, Nicolás. Post producción. La cultura como escenario: modos en que el arte reprograma el mundo contemporáneo. Buenos Aires, Adriana Hidalgo, 2004.

Buksdorf, Daniela. "La reescritura como herramienta de respuesta literaria". $\mathrm{La} \mathrm{Pa}$ labra, n. 27,2015 , pp. 95-106.

Bürger, Peter. Teoría de la vanguardia, Trad. Tomás Bartoletti. Barcelona, Península, 2010.

Carrasco, Germán. "El baile de las máscaras”. Rémoras en tinta. Santiago, Alquimia, 2014, pp. 75-6.

Crimp, Douglas. "Sobre las ruinas del museo". Posiciones críticas. Ensayos sobre las políticas de arte y la identidad, Trad. Eduardo García. Madrid, Akal, 2005, pp. 61-72.

Ferrada, María José. Notas al margen. Santiago, Alfaguara, 2013.

Gache, Belén. Escrituras nómades. Guijón, Asturias, TREA S. L., 2016.

Genovese, Alicia. Leer poesía. Lo leve, lo grave, lo opaco. Buenos Aires, Fondo de Cultura Económica, 2011.

Goldsmith, Kenneth. Escritura no-creativa. Gestionando el lenguaje en la era digital. Trad. Alan Page. Buenos Aires, Caja Negra, 2015.

Guerrero, Gustavo. Paisajes en movimiento. Literatura y cambio cultural entre dos siglos. Buenos Aires, Eterna Cadencia, 2018.

Hernández, Biviana. "La reescritura como ejercicio de estilización paródica en Facsímil de Alejandro Zambra y 'Curriculum vitae’ de Rodrigo Lira”. Estudios Filológicos, n. ${ }^{\circ} 63,2019$, pp. 99-119.

Jelin, Elizabeth. Los trabajos de la memoria. Madrid, Siglo XxI, 2002.

Marchán Fiz, Simón. Del arte objetual al arte de concepto 1960-1974. Madrid, Akal, 1994. 
Martínez, Juan Luis. La poesía chilena. Santiago, Ediciones Archivo, 1978.

Moulian, Tomás. El consumo me consume. Santiago, LOM, 1998.

Padilla, José Ignacio. "El terreno en disputa es el lenguaje”. Revista de Crítica Literaria Latinoamericana, n. ${ }^{\circ} 76,2012$, pp. 381-404.

Pinos, Jaime. Documental. Santiago, Alquimia, 2018.

-—. "La poesía. La historia. El relámpago", 2015. Disponible en: http://letras.mysite. com/jpin181115.html (Recuperado el 13/10/2018)

-_. Almanaque. Santiago, Lanzallamas, 2010.

- - Criminal. Santiago, La Calabaza del Diablo, 2003.

Porrúa, Ana. Caligrafía tonal. Ensayos sobre poesía. Buenos Aires, Entropía, 2011.

Rancière, Jacques. El reparto de lo sensible. Santiago, LOM, 2009.

Richard, Nelly. Residuos y metáforas. Ensayos de crítica cultural sobre el Chile de la Transición. Santiago, Cuarto Propio, 1998.

Rivera Garza, Cristina. Muertos indóciles. Necroescrituras y desapropiación. México D. F., Tusquets, 2013.

Rojas, Sergio. El arte agotado. Magnitudes y representaciones de lo contemporáneo. Santiago, Sangría, 2012.

Sanders, Ed. Investigative Poetry. San Francisco, City Lights, 1976.

Sepúlveda, Magda. Ciudad quiltra. Poesía chilena 1973-2013. Santiago, Cuarto Propio, 2013.

Soto Román, Carlos. 11. Santiago, Autoedición, 2017.

- - Haikú minero. Santiago, La Calabaza del Diablo, 2006.

Valdés, Adriana. Redefinir lo humano: las humanidades en el siglo XXI. Valparaíso, Universidad de Valparaíso, 2017.

Enviado: 3 de febrero de 2019 Aceptado: 17 de septiembre de 2019 